\title{
Defining the Normal Dorsal Contour of the Corpus Callosum with Time
}

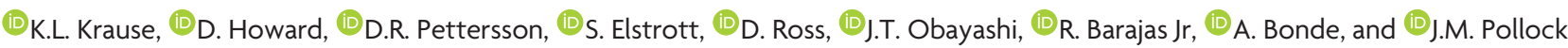

\begin{abstract}
BACKGROUND AND PURPOSE: Morphological changes of the corpus callosum have been associated with a large number of congenital neurocognitive and psychiatric disorders. Focal defects or notches of the dorsal surface of the corpus callosum have not been well characterized. Our purpose was the following; 1) to characterize the dorsal contour of the corpus callosum during the life span, 2) to characterize the relationship of contour deviations to neighboring vessels, and 3) to determine whether contour deviations are congenital or acquired.
\end{abstract}

MATERIALS AND METHODS: We retrospectively reviewed normal sagittal Tl-weighted brain MR images. A "notch" was defined as a concavity in the dorsal surface at least $1 \mathrm{~mm}$ in depth. The corpus callosum was considered to be "undulating" if there were $>2$ notches, including an anterior and posterior notch. The presence of a pericallosal artery and its relationship to a notch were assessed.

RESULTS: We reviewed 1639 MR imaging studies, spanning 0-89 years of age. A total of 1102 notches were identified in 823 studies; 344 (31\%) were anterior, 660 (60\%) were posterior, and $98(9 \%)$, undulating. There was a positive correlation between the prevalence $(P<.001)$ and depth $(P=.028)$ of an anterior notch and age and a negative correlation between the prevalence of a posterior notch and age $(P<$ $.001)$. There was no difference between patient sex and corpus callosum notching $(P=.884)$. Of the 823 studies with notches, 490 (60\%) were associated with a pericallosal artery $(P<.001)$.

CONCLUSIONS: The prevalence and depth of notches in the anterior corpus callosum increase significantly with age; this finding suggests that most notches are acquired. There is a significant positive association between the presence of a corpus callosum notch and adjacent pericallosal arteries, suggesting that this may play a role in notch formation.

ABBREVIATIONS: $C C=$ corpus callosum; FAS $=$ fetal alcohol syndrome

$\mathrm{T}$ he corpus callosum (CC) is the midline commissural white matter tract that connects the 2 cerebral hemispheres. It is located at the depth of the interhemispheric fissure and forms the roof of the lateral ventricles. It is divided into 5 named sections from anterior to posterior: rostrum, genu, body, isthmus, and splenium. ${ }^{1,2}$ The CC is the largest white matter tract in the brain, with approximately 180 million callosal fibers, ${ }^{3}$ which allow sophisticated interhemispheric communication. With such physiologic importance, the CC has a blood supply from both the anterior and posterior circulation by way of a number of different pericallosal vessels. $^{4,5}$

The MR imaging characteristics of the CC and neighboring ves-

Received May 21, 2018; accepted after revision October 6.

From the Departments of Radiology (D.H., D.R.P., S.E., R.B., A.B., J.M.P.) and Neurological Surgery (K.L.K., D.R., J.T.O.), Oregon Health \& Science University, Portland, Oregon.

Please address correspondence to Jeffrey M. Pollock MD, Department of Radiology, Oregon Health \& Science University, 3181 SW Sam Jackson Park Rd, CR 135,

Portland, OR 97239; e-mail: pollockj@ohsu.edu

http://dx.doi.org/10.3174/ajnr.A5886 sels have been well-described ${ }^{2}$ and are becoming more detailed as MR imaging technologies continue to advance. In turn, a number of reports also describe the MR imaging characteristics of a wide variety of congenital and acquired CC pathologies, such as fetal alcohol spectrum disorders. ${ }^{1,2,6-11}$ Thus, the intrinsic morphology of the CC has become the subject of intense investigation and debate in its association with multiple cognitive and neuropsychiatric disorders. ${ }^{9,12-14}$

The MR imaging characteristics of the dorsal callosal contour and its intimate association with pericallosal blood vessels have not been well studied or described in the literature. Given that the morphology of the CC is so carefully scrutinized in a number of pathologic conditions, our objective was to investigate the normal dorsal morphology of the CC during the human life span, its anatomic relationship to neighboring vessels, and whether any contour deviation is a congenital or acquired etiology.

\section{MATERIALS AND METHODS Study Population}

This retrospective, single-center study was approved by the institutional review board with a waiver of patient consent. Initially, 

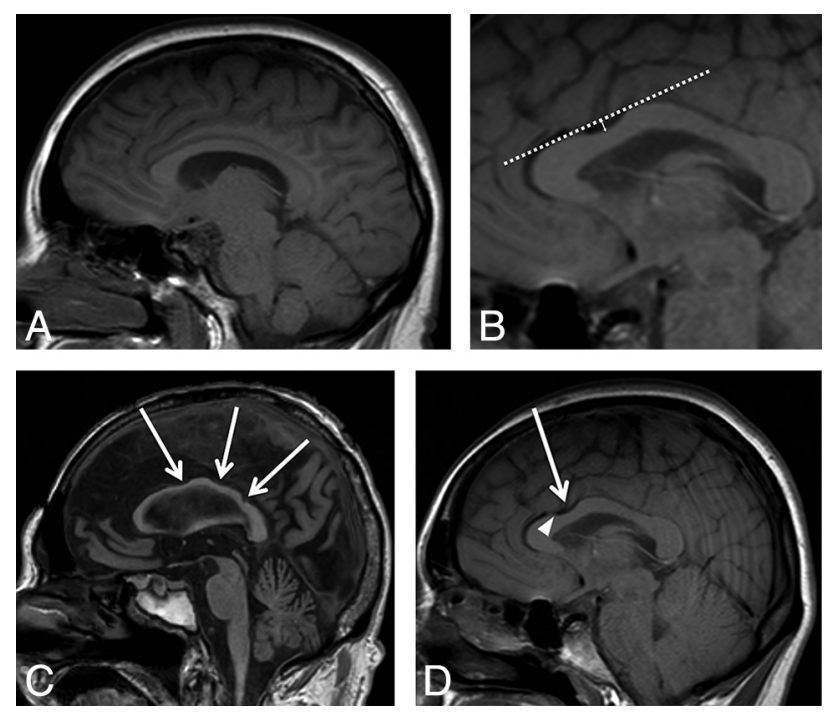

FIG 1. A, Midline sagittal T1-weighted image shows an example of a normal corpus callosum without evidence of anterior or posterior notching. B, A "notch" was defined as a depression in the dorsal surface whose depth was at least $1 \mathrm{~mm}$ from a tangential (dashed) line to the surface of the CC. The solid arrow line shows a 3-mm-deep anterior notch. $C$, Three areas of notching indicated by the white arrows correspond to an undulating configuration. D, Midline sagittal T1weighted image shows that a 3-mm anterior notch (arrow) is present. The flow void from the pericallosal artery is visualized extending into the notch (arrowhead).

3800 consecutive brain MR imaging examinations with reported impressions containing the keywords "normal" or "no acute process" were reviewed. These data were then screened for all radiographically normal study findings, spanning patient ages 1 day $(0$ years) to 90 years, that contained a diagnostic-quality midline sagittal T1-weighted image. Studies were excluded for any pathologic process, including but not limited to developmental anomalies, hydrocephalus, intracranial hemorrhage, infarction, encephalomalacia, demyelinating disease, trauma, malignancy, any surgical intervention, or motion-limited examinations.

A team of neuroradiologists and neurosurgeons then visually inspected the dorsal surface of each CC on a midline sagittal T1weighted image. A CC was designated "normal" if the dorsal surface contained no notching (Fig 1A). A "notch" was defined as a focal concavity in the dorsal surface the depth of which was at least $1 \mathrm{~mm}$ from a tangential line to the surface of the CC (Fig $1 B$ ). The notch was noted to be in either the anterior or posterior half of the body of the CC. The CC was considered "undulating" if there were $>2$ notches, including both an anterior and posterior notch (Fig $1 C$ ). The depth and location of the notch was recorded. Each image was also examined for the presence of a visible pericallosal artery flow void and whether the artery was seen within the notch (Fig 1D).

\section{Statistical Analysis}

Subjects were sorted by age and grouped into 5 -year increments, starting at age zero. A Poisson regression model was used to determine whether the prevalence of a notch changes with time, and a Spearman $\rho$ correlation was used to determine whether the depth of a notch changes with time. A Student $t$ test was used to determine whether patient sex affects the depth of anterior and
Retrospective review summary of brain MR imaging studies, notch count, and position

\begin{tabular}{lc}
\hline \multicolumn{1}{c}{ Review Summary } \\
\hline Brain MR imaging studies reviewed (No.) & 1639 \\
Brain MR imaging studies, with notches (No.) & 823 \\
Notches identified in 823 MR imaging studies (No.) & 1102 \\
Female (No.) (\%) & $919 ; 56$ \\
$\quad$ Notch identified & $460 ; 50$ \\
Male (No.) (\%) & $720 ; 44$ \\
$\quad$ Notch identified & $363 ; 50$ \\
Anterior position (No.) (\%) & $344 ; 31$ \\
Posterior position (No.) (\%) & $660 ; 60$ \\
Undulating, >2 notches (No.) (\%) & $98 ; 9$ \\
Pericallosal artery notch association (No.) (\%) & $490 ; 60$ \\
\hline
\end{tabular}

posterior notches. $\chi^{2}$ tests were used to determine whether sex or the presence of a blood vessel significantly affects the presence of a notch. Logistic regression was used to determine whether age is a significant predictor variable for undulation, with undulation as a binary dependent variable. Logistic regression was also used to determine whether age is a significant predictor variable for the occurrence of anterior and posterior notches. Statistical analysis was undertaken using SPSS Statistics, Version 24 (IBM, Armonk, New York), and $P$ values were considered significant at $<.05$.

\section{RESULTS}

Retrospective review revealed 1639 unique brain MR imaging studies that met study inclusion criteria; 919 (56\%) were female patients and 720 (44\%) were male. Ages ranged from 0 to 89 years. There was a total of 1102 notches identified in 823 MR imaging studies; $344(31 \%)$ were located in the anterior half, and 660 $(60 \%)$ were in the posterior half of the corpus callosum. There were $98(9 \%)$ studies that demonstrated an undulating pattern. From the total of 919 females and 720 males, 460 females (50\%) and 363 males (50\%) demonstrated evidence of a notch. There was no significant difference between sex and the prevalence of a notch $(P=.884)$ (Table).

The prevalence of an anterior or posterior notch was significantly affected by age (Fig 2). There was a significant positive correlation between the prevalence of an anterior notch and advancing age $(P<.001, \mathrm{OR}=1.095 ; 95 \% \mathrm{CI}, 1.067-1.123)$, so the odds of an anterior notch increased by 1.1 times for each age category. Conversely, there was a significant negative correlation between the prevalence of a posterior notch and age $(P<.001$, OR $=0.967 ; 95 \% \mathrm{CI}, 0.948-0.987)$, so the odds of a posterior notch decreased by 0.967 for each age category. Age was also found to be a statistically significant predictor of undulation of the corpus callosum $(P=.002$, OR $=1.106$; 95\% CI, $1.008-$ $1.025)$. We then specifically examined the 0 - to 1 -year of age subpopulation cohort $(n=24)$ to determine the earliest prevalence of notches. This subpopulation had a $12 \%$ prevalence of an anterior notch and a $21 \%$ prevalence of a posterior notch.

Age had a variable effect on the depth of the notch (Fig 3). The average depth of the anterior notch over all age groups was 1.5 $\mathrm{mm}$, and that of the posterior notch was $1.7 \mathrm{~mm}$. The depth of the anterior notch significantly increased $[\operatorname{Rs}(345)=0.118, P=.028]$ with increasing age. In contrast, age had no significant effect on the depth of the posterior notch $[\operatorname{Rs}(658)=0.019, P=.622]$. Sex also did not affect the depth of either the anterior $[\mathrm{t}(343)=1.613$, $P=.147]$ or posterior $[\mathrm{t}(656)=-0.253, P=.330]$ notch. 


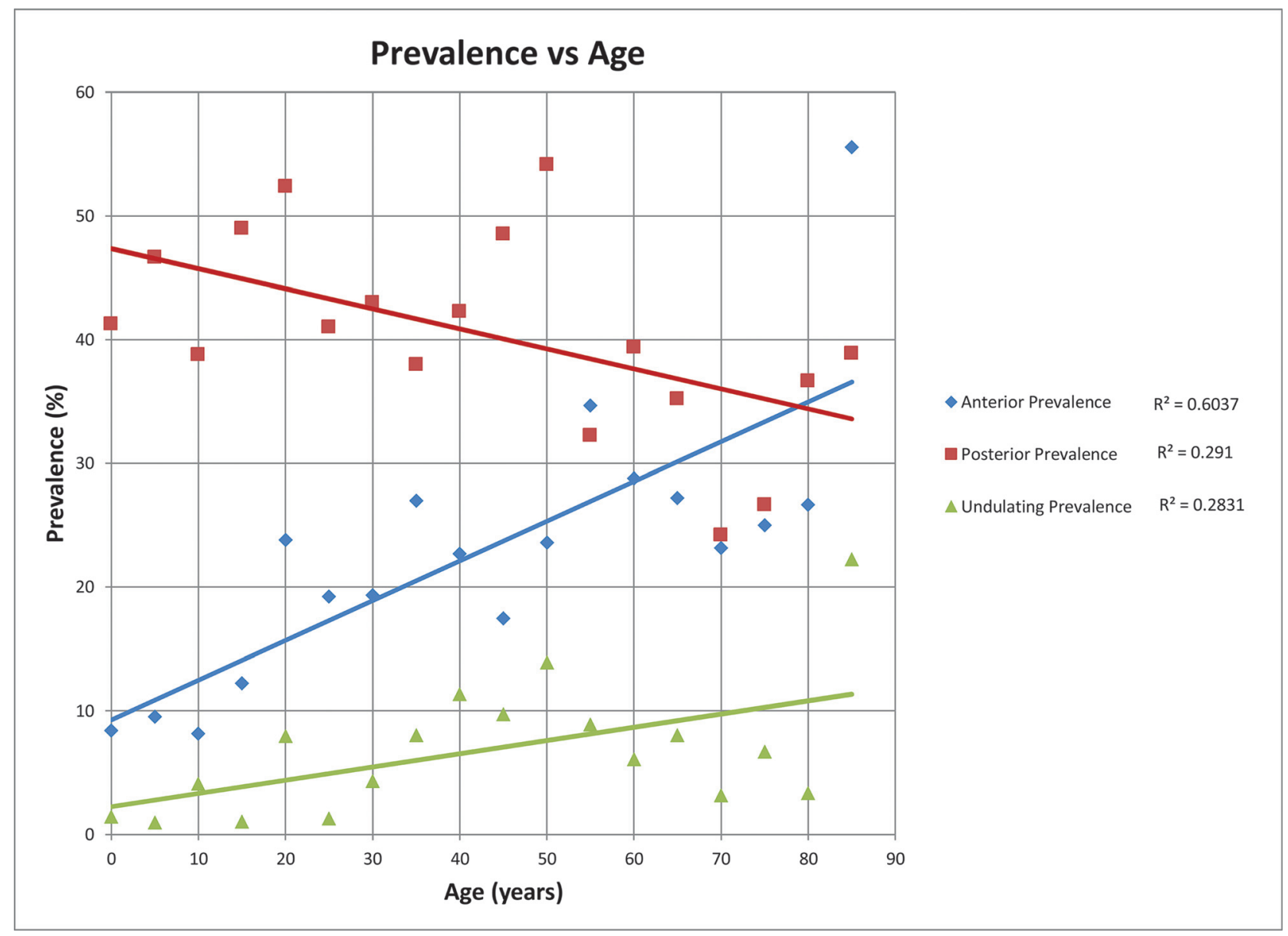

FIG 2. Scatterplot of prevalence versus age in 5 -year increments. The posterior notch prevalence (red squares and red line) decreases with time, $R^{2}=0.29$. The anterior notch prevalence (blue diamonds and blue line) increases with time, $R^{2}=0.60$. The undulating pattern prevalence (green triangles and green line) also increases with time, $R^{2}=0.28$.

There were $604(37 \%)$ studies in which a pericallosal artery flow void was identified. In 490 of the 823 (60\%) studies in which a CC notch was present, a pericallosal artery flow void was significantly associated with the presence of a notch $(P<.001)$ (Table).

\section{DISCUSSION}

To our knowledge, this is the first study describing the MR imaging characteristics of the dorsal CC surface across the human life span. Here we demonstrate that notching of the dorsal CC surface is present in infancy in up to $21 \%$ of individuals, suggesting that it can be a physiologic anatomic feature. This study shows that the strongest correlation is between an anterior notch prevalence and increasing age. The posterior notch and undulating pattern had a moderate correlation. These dynamic age-related changes suggest that notching is an acquired anatomic feature in most individuals.

It has been previously demonstrated that the morphology of the CC does not remain static with time. Tanaka-Arakaw et al ${ }^{15}$ reported that the callosal growth from 0 to 25 years of age is nonlinear; there is an initial marked growth in the total crosssectional area in the first few months to years of life, which then plateaus during later childhood and adolescence. Then, after 16 years of age, the total area of the CC progressively declines throughout the life span. ${ }^{16-18}$ Furthermore, the individual components of the CC develop at different rates. ${ }^{2}$ There is an initial growth of the genu beginning at birth to 5-6 years, followed by subsequent growth of the splenium until 10-12 years. ${ }^{19,20} \mathrm{Al}-$ though debated in the literature, these changes do not seem to be sex-dependent. Multiple studies have demonstrated that there is not a consistent statistical change in the absolute callosal area between men and women throughout the life span. ${ }^{15,16,20-23}$

Our study also supports the dynamic evolution of the CC with time. Our data suggest that as patients age, the prevalence and depth of an anterior notch in the dorsal callosal surface increase significantly. The depth of the anterior notch is most shallow during childhood and adolescence and then gradually increases with advancing age. It seems conceivable that as the CC ages and its midline cross-sectional area diminishes, the notch depth and thus its prominence become more obvious.

In contrast, however, the prevalence of the posterior notch decreased with age in our study, and the depth did not significantly differ with time. It is known that in the older population, the total white matter volume and the corpus callosum crosssectional area decrease across time. ${ }^{16-18}$ Concurrently, there is also a compensatory increase in the ventricular volume from brain atrophy, leading to a more rounded contour and relative flattening of the posterior callosal surface compared with the younger population. ${ }^{24}$ Hypothetically, this flattening of the CC 


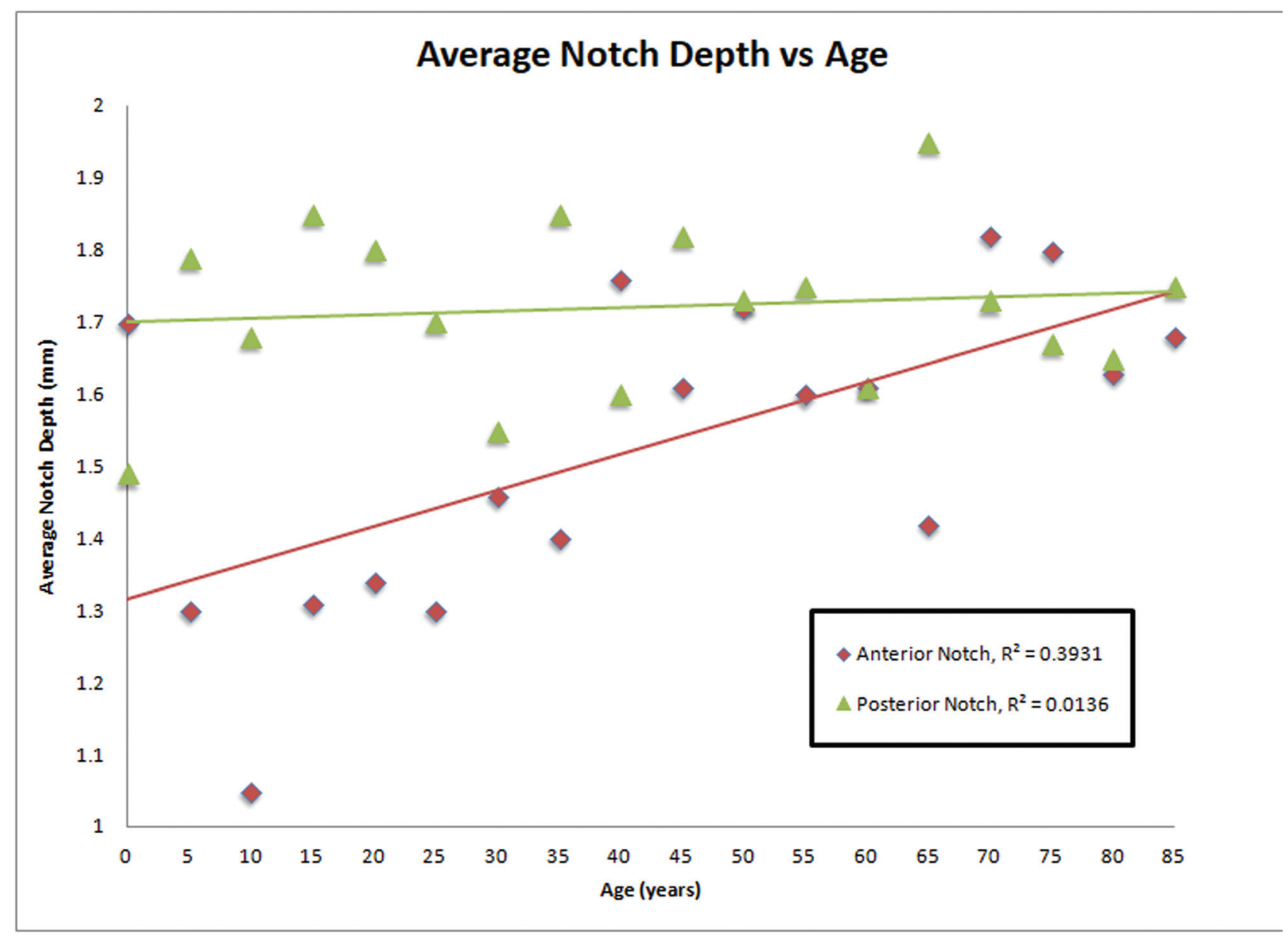

FIG 3. Scatterplot of notch depth (millimeters) versus age. No significant difference is seen in the depth of the posterior notch with increasing age $\left(R^{2}=0.01\right)$. There is a significant increase in the depth of the anterior notch with increasing age $\left(R^{2}=0.39\right)$.

with time could account for the decreasing prevalence of a posterior notch with increasing age. The posterior notch in the younger population was frequently a manifestation of having a thicker splenium than in the older population. In these younger patients, the thicker splenium created a measurable notch based on our methodology, which may also account for the decreasing prevalence with increasing age. Alternatively, the decrease in notching posteriorly with age might be due to atrophy of the posterior body and splenium of the CC due to biparietal pathologies.

We found that the prevalence of an anterior notch at any age is significantly correlated with the presence of a neighboring blood vessel. The CC is supplied by an extensive network of anastomosing vessels between the anterior and posterior cerebral arteries. The rostrum, genu, and body are mostly supplied by the pericallosal artery, a branch of the anterior cerebral artery. As demonstrated in a gross anatomic study by Türe et al, ${ }^{4}$ in $60 \%$ of specimens, the pericallosal artery was entirely within the callosal sulcus, coursing along the superficial dorsal aspect of the CC. Another $30 \%$ of specimens demonstrated vessels with an irregular course through the callosal sulcus, and only $10 \%$ were not associated with the CC at all. The terminal segment of the pericallosal artery then anastomoses with the posterior pericallosal artery, a branch of the posterior cerebral artery, which supplies most of the splenium.

Given this extensive, intimate association between the perical- losal vasculature and dorsal callosal surface, our data suggest that the etiology of a callosal notch on MR imaging may be an effect of the pericallosal artery either directly indenting or focally obscuring the CC along its course or falling into an adjacent notch. Arteries are well-known for distorting adjacent white matter structures such as the pons and medulla in cases of dolichoectasia of the vertebral artery. ${ }^{25}$ It seems plausible that with time, hypertrophy or increased tortuosity of the pericallosal artery could similarly distort the contour of the adjacent CC surface. Increased tortuosity of the vessel with time could account for the increasing prevalence of undulation of the dorsal surface as the CC accumulates additional notches. This finding may be compounded by normal callosal atrophy with aging. As the cross-sectional area of the CC diminishes with time, the vessels lose their normal support from the callosal surface. This, in turn, could lead to a vessel "falling" into an adjacent notch or "draping" of pericallosal vessels over the CC, further providing the appearance or deepening of a callosal notch on MR imaging. Similarly, the increase in anterior notching prevalence with age might be due to the much larger diameters of the proximal A2 vessels than the smaller, less pulsatile posterior vessels.

Describing the dorsal contour of the CC with time in a large population can help us better classify findings as normal, abnormal, acquired, or congenital. The morphology of the CC has been suggested to play a role in a number of different 
neurocognitive and psychiatric disorders. In particular, the CC has been widely studied in fetal alcohol syndrome (FAS), ${ }^{9,13,14,26,27}$ which affects approximately $2 \%-5 \%$ of the population in the United States. ${ }^{28,29}$ An article by Riley et al, ${ }^{9}$ from 1995, postulated that focal abnormalities or what we refer to as "notches" of the CC might be secondary to insults that occur after its complete formation. The Riley article itself does not address or describe these focal abnormalities but, ironically, remains highly cited in the medicolegal literature for establishing focal abnormalities of the CC as part of the FAS spectrum. ${ }^{9}$ When we further analyzed our patients younger than 1 year of age to determine the percentage of our population that might have congenital notches, there was a $12 \%$ anterior notch prevalence and a $21 \%$ posterior notch prevalence. The discrepancy between the low prevalence of FAS in the population $(2 \%-5 \%)$ and high prevalence of notches of the CC in our earliest age group (12\%-21\%) suggests that notching is unlikely to be directly associated with FAS. However, the significance of the prevalence discrepancy may be limited by the small sample size of patients younger than 1 year of age $(n=$ 24 ) in our study and thus may warrant further investigation to more accurately define these percentages.

It follows that this study is intrinsically limited by its narrow focus of only examining the dorsal surface of the CC. Furthermore, this was not a longitudinal study because single patients were not followed across time to track their potential development of notches. Additionally, this patient population represents a regional sample, and a similar analysis in a different region might result in different values. This is a purely radiographic study, and although each subject was examined for any intracranial pathology, we do not have any data that describe the clinical functionality of these patients. Other more global observations that may influence CC morphology, such as callosal area or total cerebral volume, were not quantified. Furthermore, we only measured the absolute depth of the notch but did not measure the depth relative to the thickness of the CC. Studies containing small-vessel ischemic changes or studies with generalized cerebral atrophy were not excluded. These are both states that could influence CC volume. Finally, the study relied on flow voids to locate the pericallosal artery and did not have dedicated angiographic correlates. These could be areas of future study.

\section{CONCLUSIONS}

Analysis of $>1600$ brain MR imaging studies suggests that the presence of a dorsal callosal notch can be a common anatomic variant, affecting $50 \%$ of both men and women. The correlation of a posterior notch and an undulating pattern with age was moderate, while there was a strong correlation of anterior notch prevalence with age. The prevalence and depth of a notch are dynamic phenomena that change throughout the life span, providing evidence that notching can also be an acquired finding that, at least in some cases, is the result of normal aging. Furthermore, the presence of a notch can also be associated with a neighboring pericallosal artery.

\section{ACKNOWLEDGMENTS}

We thank Shirley McCartney $\mathrm{PhD}$ for her assistance with manuscript preparation and formatting.

Disclosures: Ramon Barajas-UNRELATED: Grant: National Cancer Institute, Comments: 3 R01 CA137488-22S1.* *Money paid to the institution.

\section{REFERENCES}

1. Battal B, Kocaoglu M, Akgun V, et al. Corpus callosum: normal imaging appearance, variants and pathologic conditions. J Med Imaging Radiat Oncol 2010;54:541-49 CrossRef Medline

2. Georgy BA, Hesselink JR, Jernigan TL. MR imaging of the corpus callosum. AJR Am J Roentgenol 1993;160:949-55 Medline

3. Devinsky O, Laff R. Callosal lesions and behavior: history and modern concepts. Epilepsy Behav 2003;4:607-17 CrossRef Medline

4. Türe U, Yaşargil MG, Krisht AF. The arteries of the corpus callosum: a microsurgical anatomic study. Neurosurgery 1996;39:1075-84; discussion 1084-85 CrossRef Medline

5. Kahilogullari G, Comert A, Ozdemir M, et al. Arterial vascularization patterns of the splenium: an anatomical study. Clin Anat 2013; 26:675-81 CrossRef Medline

6. Bourekas EC, Varakis K, Bruns D, et al. Lesions of the corpus callosum: MR imaging and differential considerations in adults and children. AJR Am J Roentgenol 2002;179:251-57 CrossRef Medline

7. Byard RW. The corpus callosum and forensic issues: an overview. $J$ Forensic Sci 2016;61:979-83 CrossRef Medline

8. Renard D, Castelnovo G, Campello C, et al. An MRI review of acquired corpus callosum lesions. J Neurol Neurosurg Psychiatry 2014; 85:1041-48 CrossRef Medline

9. Riley EP, Mattson SN, Sowell ER, et al. Abnormalities of the corpus callosum in children prenatally exposed to alcohol. Alcohol Clin Exp Res 1995;19:1198-202 Medline

10. Uchino A, Takase Y, Nomiyama K, et al. Acquired lesions of the corpus callosum: MR imaging. Eur Radiol 2006;16:905-14 Medline

11. Hyun Yoo J, Hunter J. Imaging spectrum of pediatric corpus callosal pathology: a pictorial review. J Neuroimaging 2013;23:281-95 CrossRef Medline

12. Coger RW, Serafetinides EA. Schizophrenia, corpus callosum, and interhemispheric communication: a review. Psychiatry Res 1990;34: 163-84 CrossRef Medline

13. Donald KA, Eastman E, Howells FM, et al. Neuroimaging effects of prenatal alcohol exposure on the developing human brain: a magnetic resonance imaging review. Acta Neuropsychiatr 2015;27: 251-69 CrossRef Medline

14. Norman AL, Crocker N, Mattson SN, et al. Neuroimaging and fetal alcohol spectrum disorders. Dev Disabil Res Rev 2009;15:209-17 CrossRef Medline

15. Tanaka-Arakawa MM, Matsui M, Tanaka C, et al. Developmental changes in the corpus callosum from infancy to early adulthood: a structural magnetic resonance imaging study. PLoS One 2015;10: e0118760 CrossRef Medline

16. Allen LS, Richey MF, Chai YM, et al. Sex differences in the corpus callosum of the living human being. J Neurosci 1991;11:933-42 CrossRef Medline

17. Doraiswamy P, Figiel G, Husain M, et al. Aging of the human corpus callosum: magnetic resonance imaging in normal volunteers. J Neuropsychiatry Clin Neurosci 1991;3:392-97 CrossRef Medline

18. Hayakawa K, Konishi Y, Matsuda T, et al. Development and aging of brain midline structures: assessment with MR imaging. Radiology 1989;172:171-77 CrossRef Medline

19. Knyazeva MG. Splenium of corpus callosum: patterns of interhemispheric interaction in children and adults. Neural Plast 2013;2013: 1-12 CrossRef Medline

20. Vannucci RC, Barron TF, Vannucci SJ. Development of the corpus callosum: an MRI study. Dev Neurosci 2017;39:97-106 CrossRef Medline 
21. Rajapakse JC, Giedd JN, Rumsey JM, et al. Regional MRI measurements of the corpus callosum: a methodological and developmental study. Brain Dev 1996;18:379-88 CrossRef Medline

22. Jäncke L, Staiger JF, Schlaug G. et al. The relationship between corpus callosum size and forebrain volume. Cereb Cortex 1997;7:48-56 CrossRef Medline

23. Kertesz A, Polk M, Howell J, et al. Cerebral dominance, sex, and callosal size in MRI. Neurology 1987;37:1385-88 Medline

24. Scahill RI, Frost $C$, Jenkins R, et al. A longitudinal study of brain volume changes in normal aging using serial registered magnetic resonance imaging. Arch Neurol 2003;60:989-94 CrossRef Medline

25. Resta M, Gentile MA, Di Cuonzo F, et al. Clinical-angiographic correlations in 132 patients with megadolichovertebrobasilar anomaly. Neuroradiology 1984;26:213-16 CrossRef Medline
26. Sowell ER, Mattson SN, Thompson PM, et al. Mapping callosal morphology and cognitive correlates: effects of heavy prenatal alcohol exposure. Neurology 2001;57:235-44 CrossRef Medline

27. Yang Y, Phillips OR, Kan E, et al. Callosal thickness reductions relate to facial dysmorphology in fetal alcohol spectrum disorders. Alcohol Clin Exp Res 2012;36:798-806 CrossRef Medline

28. May PA, Baete A, Russo J, et al. Prevalence and characteristics of fetal alcohol spectrum disorders. Pediatrics 2014;134:855-66 CrossRef Medline

29. May PA, Gossage JP, Kalberg WO, et al. Prevalence and epidemiologic characteristics of FASD from various research methods with an emphasis on recent in-school studies. Dev Disabil Res Rev 2009; 15:176-92 CrossRef Medline 